\title{
Grid Integrated Wind Energy Storage System for Linear and non-Linear Loads
}

\author{
Dr. K. Suresh ${ }^{1 *}$, A. R. Vijay Babu ${ }^{2}$, P. M. Venkatesh ${ }^{3}$ \\ ${ }^{12} 3$ Vignans foundations for Science, Technology and Research, Vadlamudi, Andhra Pradesh, India- 522213. \\ *Corresponding author E-mail:sureshk340@gmail.com
}

\begin{abstract}
The proposed system also has boost converter, bidirectional DC-DC converter and inverter for grid and wind energy integration. The boost inverter/buck rectifier in this system is controlled by ANFIS controller is for better output, boost and bidirectional DC-DC converters are controlled by PID controller in closed loop. Overall operations are based on modes main controller speedgoat, which is control the system operation in different modes. Any variation happening in the input, storage and load parameters speedgoat changing the mode and operate the system is in effective way. This paper presents harnessing of maximum wind energy from natural resource whenever it's available. The power electronic converters role is important In between sources and load. The load may be linear and non-linear in nature, so converters performance decides the efficiency of the system. Proper controller can switch the converter in the desired time and improve the system performance and stability. Many controllers are suggests to control the converter to get better performance in at output side.
\end{abstract}

Keywords:ANFIS Controller, Bidirectional converter, Speedgoat, Wind energy.

\section{Introduction}

In conventional energy storage systems the converters like uncontrolled AC-DC rectifier, PID controlled boost converter, PID controlled bidirectional DC-DC converters are also using for power conversion stages with grid tied inverter [4]. These converters are connected between Wind Energy Conversion System (WECS), Energy Storage Device (ESD) and load/grid for effective wind energy harnessing; the converters in all the stages are controlled by separate controllers. But converters in these systems are operating in closed loop but the overall system is operated by open loop configuration. There are some serious dis-advantages related to this open loop configuration such as non-reliable, inefficient operation and less utilization of natural energy. To overcome these draw back the system should be operate in closed loop from some parameter considerations. This proposed system considers the parameters such as wind speed (v), state of charge (\%) and load position (ON/OFF). Based on these parameters the speedgoat generates control signal and given to control breakers which operates the system in different modes for an effective operation with linear and non-linear load.

\section{Analysis of Wind Energy System}

Each stage of conversion is analysed and composed by mathematical equations. Every stages of conversion consist of converters and controllers in closed loop and overall system is controlled by separate main controller called speedgoat.

\subsection{Wind energy conversion}

The design of wind turbine is taken from [1], horizontal axis wind turbine has to analysed from equations 1,2 and 3. Wind passes through in area area (A) and wind speed (v) of a particular velocity. The power of wind is expressed in equation 1.

$p=0.5 * \rho^{*} A * v^{3}$

Mechanical power is expressed in the following equation 2.

$p_{T}=0.5 * \rho^{*} A *\left(v_{1}+v_{2}\right) *\left(v_{1}^{2}+v_{2}^{2}\right)$

The rotor coefficient is expressed by the following equation 3

$C_{p}=\frac{P_{T}}{P}=0.5 *\left(1-\frac{v_{2}^{2}}{v_{1}^{2}}\right) *\left(1-\frac{v_{2}}{v_{1}}\right)$

\subsection{PMSG}

Mathematical modeling of Permanent Magnet Synchronous Generator (PMSG) can be written in the following equations 4 and 5.

$\frac{d i_{d}}{d t}=\frac{R_{a}}{L_{d}} i_{d}=\frac{L_{q}}{L_{d}} p \omega i_{q}+\frac{1}{L_{d}} u_{d}$

$\frac{d i_{d}}{d t}=\frac{R_{a}}{L_{q}} i_{q}=\frac{L_{d}}{L_{q}} p \omega i_{d}+\frac{1}{L_{d}} p \omega \phi_{m}+\frac{1}{L_{q}} u_{q}$ 
The EMF equation of PMSG is written in equation 6.

$$
E_{p h}=4.44 f \phi T_{p h} K_{w}
$$

\subsection{Rectifier unit}

The three phase AC power from permanent magnet synchronous generator is supply to 3 phase bridge rectifier for AC-DC conversion. The phase voltage amplitude $\mathrm{V}_{\mathrm{m}}$ and output average voltage $\mathrm{V}_{\mathrm{o}}$ is expressed by the equations $7 \& 8$.

$$
V_{m}=V_{r m s} \sqrt{2}
$$

$V_{r}=\frac{3 \sqrt{2}}{\Pi} V m$

\subsection{Unidirectional converter (UDC)}

The output of unidirectional boost converter can be analysed in the input voltage and duty cycle. All stages of boost mode are controlled by adjusting the duty cycle automatically with closed loop controller. The output voltage and duty cycle is expressed by the equations 9 and 10.

$V_{b}=\frac{V_{r}}{(1-D)}$

$\frac{T_{o n}}{T_{\text {on }}+T_{\text {off }}}=\frac{T_{\text {on }}}{T_{s}}=D$

\subsection{Bidirectional converter (BDC)}

The primary switch Q1 is ON position during boost mode it is expressed in equation 11

$$
\begin{gathered}
\left.\dot{X}=A_{1} X+B_{1} V_{S}\right\rangle \\
V_{\text {batt }}=C_{1}^{T} X
\end{gathered}
$$

Where, $\mathbf{x}=$ state variable vector, $\mathrm{I}_{\mathrm{L}}$ is inductor current and $\mathrm{V}_{\mathrm{c}}$ is capacitor voltage. It consists of inductor and capacitor to represents current and voltage .It can be re-written in equation 12 .

$$
\begin{gathered}
{\left[\begin{array}{c}
\frac{d i_{L}}{d t} \\
\frac{d v_{c}}{d t}
\end{array}\right]=\left[\begin{array}{cc}
-\frac{r_{c}+r_{L}}{L} & -\frac{1}{L} \\
\frac{1}{C} & -\frac{1}{R C}
\end{array}\right] \times\left[\begin{array}{c}
\frac{i_{L}}{v_{c}}
\end{array}\right]+\left[\begin{array}{c}
\frac{1}{2 L N} \\
0
\end{array}\right] v_{s}} \\
V_{b a t t}=\left[\begin{array}{ll}
r_{c} & 1
\end{array}\right] \times\left[\begin{array}{l}
i_{L} \\
v_{c}
\end{array}\right]
\end{gathered}
$$

The state vector $\mathrm{X}$ dot is expressed in state variables such as $\mathrm{A}_{2}$ and $\mathrm{B}_{2}$. The time interval of the primary switches is $\mathrm{ON}$ are expressed in the equation 13 .

$$
\begin{gathered}
\left.\dot{X}=A_{2} X+B_{2} V_{S}\right\rangle \\
V_{\text {batt }}=C_{2}^{T} X
\end{gathered}
$$

Which are re-written in the equation 14.

$$
\left[\begin{array}{c}
\frac{d i_{L}}{d t} \\
\frac{d v_{c}}{d t}
\end{array}\right]=\left[\begin{array}{cc}
-\frac{r_{c}+r_{L}}{L} & -\frac{1}{L} \\
\frac{1}{C} & -\frac{1}{R C}
\end{array}\right] \times\left[\begin{array}{c}
i_{L} \\
v_{c}
\end{array}\right]+\left[\begin{array}{l}
0 \\
0
\end{array}\right] v_{s}
$$

The small signal analysis of AC perturbation in a DC operating point, the circuit variables is added to the ac perturbations is expressed in equation 15 .

$$
d_{s s}=D_{s s}+\hat{d_{s s}} \quad x=X+\hat{x} \quad v_{s}=V_{s}+\hat{v_{s}}
$$

AC small signal is denoted by cap symbol. The perturbation approximation is small so negligible. Steady state value is expressed in equation 16.

$$
\frac{\hat{d_{s s}}}{D_{s s}}<<1 \quad \frac{\hat{x}}{X}<<1 \quad \frac{\hat{v_{s}}}{V_{s}}<<1
$$

It provides the final linearized ac small signal model.

$\dot{\hat{x}}=A \hat{x}+B \hat{V}_{s}+\left[\left(A_{1}-A_{2}\right) X+\left(B_{1}-B_{2}\right) V_{s}\right] \hat{d}_{s s}$

The transfer function of boost converter in the boost mode operation is expressed in s-domain. Thus the s-domain form of boost converter is expressed in an equation 18.

The current-programmed state equation (19) is minimized to a function of $\mathrm{X}(\mathrm{s}) \& \mathrm{~V}_{\text {control }}(\mathrm{s})$. It allows $\mathrm{x}(\mathrm{s})$ to an expression as in $\mathrm{V}_{\text {control }}(\mathrm{s})$ in a matrix multiplication,

$$
\begin{aligned}
& {\left[\begin{array}{l}
s \hat{i_{L}}(s) \\
\hat{s} \\
v_{c}(s)
\end{array}\right]=\left[\begin{array}{cc}
-\frac{r_{c}+r_{L}}{L} & -\frac{1}{L} \\
\frac{1}{C} & -\frac{1}{R C}
\end{array}\right] \times\left[\begin{array}{c}
\hat{i_{L}}(s) \\
\hat{v_{c}}(s)
\end{array}\right]+\left[\begin{array}{c}
1 \\
2 L N \\
0
\end{array}\right] \hat{v_{s}}(s)+\left[\begin{array}{c}
V_{s} \\
2 L N \\
0
\end{array}\right] \hat{d_{s s}}(s)} \\
& \hat{\boldsymbol{X}}(s)=\left[s \boldsymbol{I}-\boldsymbol{A}^{\mathbf{1}}\right]^{\mathbf{1}} \boldsymbol{C}^{\mathbf{1}} \hat{\boldsymbol{V}}_{\text {control }}(s)
\end{aligned}
$$

Where, I = identity matrix. The small-signal expression for output voltage is given by

$$
\begin{aligned}
& \hat{v}_{\text {batt }}(s)=C \hat{x}(s) \\
& \frac{\hat{v}_{\text {batt }}(s)}{\hat{v}_{\text {control }}(s)}=G_{v f} \frac{1+\frac{s}{\omega_{s}}}{1+\frac{s}{\omega_{L} / C_{1}}+\frac{s^{2}}{\omega_{L} \omega_{c} / C_{1}}} \\
& \frac{\hat{v}_{\text {but }}(s)}{\hat{v}_{s}(s)}=A_{g g f} \frac{1+\frac{s}{\omega_{s}}}{1+\frac{s}{\omega_{L} / C_{1}}+\frac{s^{2}}{\omega_{L} \omega_{c} / C_{1}}}
\end{aligned}
$$

Where, the corner frequencies are identical to those in the controlto-output transfer function.

\subsection{ANFIS}

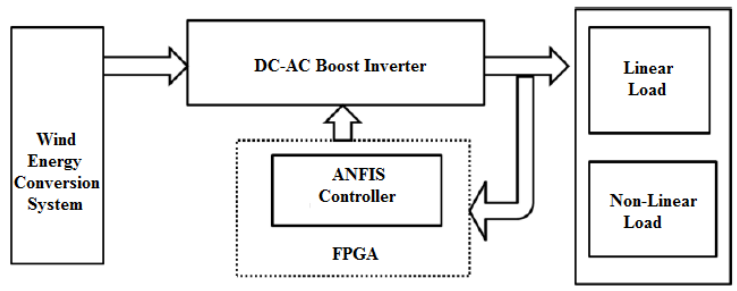

Fig 1 ANFIS Interface

ANFIS controller is connected to boost inverter is as shown in figure 1. This Set up operation is bidirectional and operates in three modes such as grid-inverter ANFIS control mode, griduncontrolled rectifier mode and stand alone ANFIS control mode. 
During first and third mode the inverter acts like a boost converter and during second mode it acts like buck rectifier.

\subsection{Simulation and Results}

Output waveforms of the entire mode are as shown in the figure 2. During the load is in ON (manual) position the control breakers $\left(\mathrm{U}_{1} \& \mathrm{U}_{2}\right), \mathrm{U}_{5} \& \mathrm{U}_{6}$ are turn $\mathrm{ON}$ by speed goat and wind power is supply to charging the battery and supply to load or else load is in OFF (manual) the control breakers $\left(\mathrm{U}_{7} \mathrm{U}_{8} \mathrm{U}_{9}\right)$ turn $\mathrm{ON}$ and supply the wind power to grid and remaining control breakers remain in OFF condition. The other two conditions are wind speed (v) is >= $5 \mathrm{~m} / \mathrm{s}$ and state of charge is in between (40-80) \%.

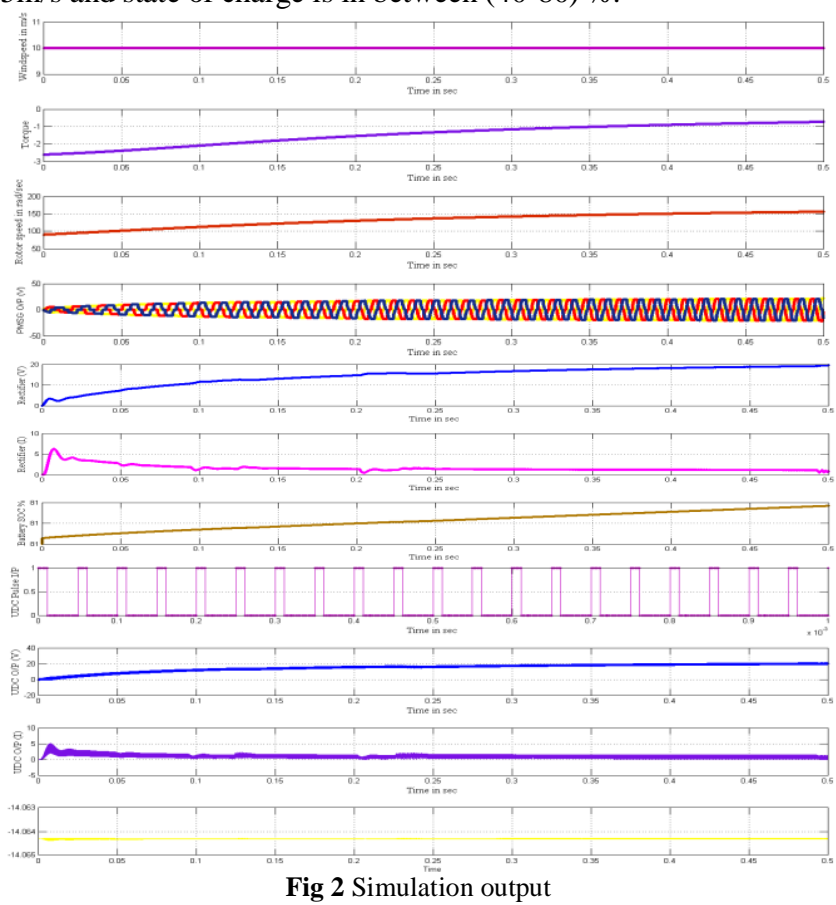

The input of the wind energy conversion system is $8 \mathrm{~m} / \mathrm{s}$. with this wind speed the output of wind profiles values of rotor torque is $0.5 \mathrm{~N}-\mathrm{m}$ and rotor speed is $160 \mathrm{rad} / \mathrm{sec}$. The output of PMSG is $24 \mathrm{~V}$. This $24 \mathrm{~V}$ AC supply is provided to converters circuit, and the final $24 \mathrm{~V}$ DC supply is given to charge the battery and also load. The input is getting from PMSG the variable $24 \mathrm{~V}$ AC supply is initially converted to DC by three phase uncontrolled bridge rectifier.

The output of bridge rectifier is $20 \mathrm{~V}$ DC because the rectifier efficiency is only $81.2 \%$. The variable $20 \mathrm{~V}$ DC voltage is converted into fixed $24 \mathrm{~V}$ DC by using unidirectional boost converter, and the converter current is almost $2 \mathrm{~A}$. This $24 \mathrm{~V}$ constant DC is supplied to the battery for charging and also supply to BDC. The bidirectional converter operates in boost mode, and the input voltage of BDC $24 \mathrm{~V}$ is step-up to $48 \mathrm{~V}$. Then the filtered pure DC is given to the inverter. Finally, the electrical AC output is applied to Load. In the other side battery also charging from UDC constant output 24V DC.

In this mode the battery is charging and also used to load, then this mode is called wind sourced battery-load mode. The carrier and reference signal is compared and the output signal of PWM controlled by the converter switches. The carrier and reference signal are compared, and PWM signal is generated given to the converter switches. The unidirectional converter output value is now obtained as $24 \mathrm{~V}$, and the bidirectional converter operates in boost mode and the getting input voltage from UDC is step-up to $48 \mathrm{~V}$, and the current value is $1 \mathrm{~A}$. Then the filtered pure DC is given to the inverter then the inverter converts DC-AC and also step-up to
$98 \mathrm{~V}$. Finally, the electrical AC output is applied to two types of loads. ANFIS controller is used to control the inverter switching and finally LC filter is used to filter the output signal Final inverter output is given to both linear and non-linear loads. The Total Harmonics Distortions (THD) of linear load is $2.57 \%$ and THD value of non-linear load is $4.35 \%$.

\section{Conclusion}

In this paper, bidirectional converter operation plays an important role for mode changing operation and its five modes of operation were analysed. Wind energy is the main input sources from renewable energy, based on this source level the operations are divided into five modes and also these modes based on state of charge in battery. The electrical energy conversion system consists of a unidirectional boost converter and bidirectional converter operates four modes in boost operation and one mode in a buck operation. Simulink model of whole system including unidirectional DC-DC boost converter, bidirectional DC-DC converters were developed for wind energy electrical system and simulation results were obtained in MATLAB/SIMULINK. Real time implementation of whole system including speedgoat real time target machine, bidirectional DC-DC converters controlled by DSPIC30F4011 were developed for wind energy electrical system and real-time results were obtained. A variety of operating conditions from different inputs were analysed. The system has a robust performance under mode changing while input wind speed changes.

\section{References}

[1] J. W. Kolar, U. Drofenik, and F. C. Zach, "Vienna rectifier II-A novel single-stage high-frequency isolated three-phase PWM rectifier system," IEEE Trans. Ind. Electron., vol. 46, no. 4 (1999), pp. 674-691.

[2] D. De and V. Ramanarayanan, "A dc-to-three-phase-ac highfrequency link converter with compensation for nonlinear distortion,” IEEE Trans. Ind. Electron., vol. 57, no. 11(2000), pp. 3669 3677.

[3] D. S. B. Weerasinghe, U. K. Madawala, D. J. Thrimawithana, and D. M. Vilathgamuwa, "A three-phase to single-phase matrix converter based bi-directional IPT system for charging electric vehicles," in Proc. 2013 IEEE ECCE Asia Down under, (2013), pp. 1240-1245.

[4] A.K. Singh, P. Das, and S. K. Panda, "A novel matrix based isolated three phase ac-dc converter with reduced switching losses," in Proc. 2015 IEEE Appl. Power Electron. Conf. Expo., (2015), pp. 18751880.

[5] M. Matsui, M. Nagai, M. Mochizuki, and A. Nabae, "Highfrequency link dc/ac converter with suppressed voltage clamp circuits-naturally commutated phase angle control with self-turn-off devices," IEEE Trans. Ind. Appl., vol. 32, no. 2,(1966) pp. 293-300.

[6] S. Norrga, "Experimental study of a soft-switched isolated bidirectional ac-dc converter without auxiliary circuit," IEEE Trans. Power Electron., vol. 21, no. 6, (2006) pp. 1580-1587.

[7] S. Norrga, S. Meier, and S. Ostlund, "A three-phase soft-switched isolated ac/dc converter without auxiliary circuit," IEEE Trans. Ind. Appl., vol. 44, no. 3, (2008), pp. 836-844.

[8] Li, Y. Zhong, and D. Xu, "Soft-switching three-phase matrix based isolated ac-dc converter for dc distribution system," in Proc. 2015 IEEE Energy Convers. Congr. Expo, (2015), pp. 6755-6761.

[9] M. Amirabadi, J. Baek, and H. A. Toliyat, "Bidirectional softswitching series ac-link inverter," IEEE Trans. Ind. Appl., vol. 51, no. 3 , (2015) pp. 2312-2320.

[10] Vijaybabu, A.R. Rajyalakshmi, V \& Suresh, K, 'Renewable Energy Integrated High Gain DC-DC Converter with Multilevel Inverter for Water Pumping', Journal of Advanced Research in Dynamical and Control Systems (2017), PP. 173-190.

[11] X. Yu, F. Jin, and M. Wang, "A novel soft-switching modulation scheme for isolated dc-to-three-phase-ac matrix-based converter using SIC device," in Proc. (2016) IEEE Energy Convers. Congr. Expo.

[12] A.R.Vijay Babu,Gorantla Srinivasa Rao, Panthalingal Manoj Kumar, "Modelling, Simulation and Analysis of Performance Charac- 
teristics of an Air Breathing ", Journal of Advanced Research in Dynamical and Control Systems, Volume 9, Issue 1, (2017) pp. 293-304

[13] Suresh, K \&Arulmozhiyal, R, 'Design and implementation of bidirectional dc-dc converter for wind energy system', Circuits and Systems, E-ISSN 2153-1285, P-ISSN 2153-1293, vol. 7, (2016) pp. 3705-3722.

[14] Z. Miao and L. Fan, "Modeling and small signal analysis of a PMSG based wind generator with sensor less maximum power extraction," in Proc. IEEE PES Gen. Meeting, Jul. (2012), pp. 1-8.

[15] B. Bryant and M. K. Kazimierczuk, "Small-signal duty cycle to inductor current transfer function for boost PWM dc-dc converter in continuous conduction mode," in Proc. IEEE ISCAS, Vancouver, BC, Canada, May 23-26, (2004), pp. 856-859. 